\title{
Correction to: Complete chloroplast genome of Firmiana major (Malvaceae), a critically endangered species endemic to southwest China
}

\author{
Ji-Dong Ya ${ }^{1} \cdot{\text { Zhi-Xiang } \mathrm{Yu}^{2} \cdot \text { Yong-Qiong Yang }}^{2} \cdot$ Shu-Dong Zhang ${ }^{1} \cdot$ \\ Zhi-Rong Zhang ${ }^{1} \cdot$ Jie Cai $^{1} \cdot$ Jun-Bo Yang ${ }^{1} \cdot$ Wen-Bin Yu ${ }^{3,4}$
}

Published online: 10 November 2017

(C) Springer Science+Business Media B.V., part of Springer Nature 2017

\section{Correction to: Conservation Genet Resour} https://doi.org/10.1007/s12686-017-0908-9

In the original publication, the third author name was misspelled as Yan-Qiong Yang. The corrected author name is given in this erratum.

Reference 2 was published incorrectly with a link which was included inadvertently. The corrected reference 2 is given below:

Hsue H-H (1984) Sterculiaceae. In: Feng K-M (ed) Flora reipublicae popularis sinacae, vol 49. Science Press, Beijing, pp 112-189.

The online version of the original article can be found under https://doi.org/10.1007/s12686-017-0908-9.

Wen-Bin Yu

yuwenbin@xtbg.ac.cn

1 Germplasm Bank of Wild Species, Kunming Institute of Botany, Chinese Academy of Sciences, Kunming 650201, Yunnan, China

2 National Nature Reserve of Panzhihua Cycad in Sichuan Province, Panzhihua 617000, Sichuan, China

3 Center for Integrative Conservation, Xishuangbanna Tropical Botanical Garden, Mengla 666303, Yunnan, China

4 Southeast Asia Biodiversity Research Institute, Chinese Academy of Science, Yezin, Nay Pyi Taw 05282, Myanmar 